\title{
ANALISIS PROFITABILITAS PERUSAHAAN MANUFAKTUR YANG GO PUBLIC YANG TERDAFTAR DI BURSA EFEK INDONESIA (BEI) SEBELUM DAN SESUDAH DIBERLAKUKANNYA UU PPH NO. 36 TAHUN 2008
}

\author{
Jessica Fergie Marentek \\ Inggriani Elim \\ Treesje Runtu \\ Fakultas Ekonomi dan Bisnis Jurusan Akuntansi \\ Universitas Sam Ratulangi Manado \\ Email : jessicafergie.69@gmail.com
}

\begin{abstract}
ABSTRAK
Dalam rangka menghadapi dampak krisis keuangan global, pemerintah menurunkan tarif $\mathrm{PPh}$ yang dikenai tarif 28\% dimulai pada tahun 2009 dan akan menjadi 25\% dimulai pada tahun 2010 . Hal ini bertujuan guna mendukung penerimaan negara dari sektor perpajakan yang lebih stabil. Ratio profitability yang dipakai peneliti dalam penelitian ini adalah Gross Profit Margin, Operating Profit Margin, Return On Investment, dan Return On Equity. Peneliti melakukan penelitian menggunakan metode analisis statistik deskriptif dengan data yang diambil dari Bursa Efek Indonesia (BEI), dan diolah menggunakan SPSS v.20 dengan program compare means-paired sample T-test. Sampel yang digunakan sebanyak 60 perusahaan manufaktur tahun 2009 dan 2010. Hasil penelitian menunjukan bahwa tidak terdapat perbedaan signifikan antara GPM tahun 2009 dan 2010 dengan nilai $t_{\text {hitung }}<$ $\mathrm{t}_{\text {tabel }}(1,729<2,045)$ pada $\alpha=0,05$. Hasil penelitian juga menunjukan bahwa tidak terdapat perbedaan signifikan antara OPM tahun 2009 dan 2010 dengan nilai $t_{\text {hitung }}<t_{\text {tabel }}(0,230<2,045)$ pada $\alpha=0,05$. Hasil penelitian juga menunjukan bahwa tidak terdapat perbedaan signifikan antara ROI tahun 2009 dan 2010 dengan nilai $t_{\text {hitung }}<t_{\text {tabel }}(0,044<2,045)$ pada $\alpha=0,05$. Dan hasil penelitian juga menunjukan bahwa tidak terdapat perbedaan signifikan antara ROE tahun 2009 dan 2010 dengan nilai $\mathrm{t}_{\text {hitung }}<\mathrm{t}_{\text {tabel }}(0,417<2,045)$ pada $\alpha=0,05$.
\end{abstract}

Kata Kunci : Profitabilitas, Perusahaan Manufaktur, Bursa Efek Indonesia (BEI), UU PPh No. 36 Tahun 2008.

\section{ABSTRACT}

In order to deal with the impact of the global financial crisis, the government lowered the tax rates at the rate of $28 \%$ starting in 2009 and will be $25 \%$ starting in 2010 . It aims to support the state revenues from taxation so it become more stable. Ratio of profitability that researchers used in this study is Gross Profit Margin, Operating Profit Margin, Return On Investment, and Return On Equity. Researchers conducted the study using descriptive statistical analysis methods with data taken from Indonesia Stock Exchange (IDX), and processed using SPSS v. 20 compare means-paired samples Ttest program. The samples are 60 manufacturing companies in 2009 and 2010. The results showed that there was no significant difference between the GPM in 2009 and 2010 with a value of $t_{\text {hitung }}<$ $\mathrm{t}_{\text {table }}(1.729<2.045)$ at $\alpha=0.05$. The results also showed that there was no significant difference between the OPM in 2009 and 2010 with a value of $t_{\text {hitung }}<t_{\text {table }}(0.230<2.045)$ at $\alpha=0.05$. The results also showed that there was no significant difference between the ROI in 2009 and 2010 with a value of $\mathrm{t}_{\text {hitung }}<\mathrm{t}_{\text {table }}(0.044<2.045)$ at $\alpha=0.05$. And the results of the study also showed that there was no significant difference between the ROE in 2009 and 2010 with a value of $t_{\text {hitung }}<t_{\text {table }}(0.417$ $<2.045$ ) at $\alpha=0.05$.

Key Words : Profitability, manufacturing companies, Indonesia Stock Exchange (IDX), UU PPh No. 36 Tahun 2008. 


\section{Latar belakang}

\section{PENDAHULUAN}

Secara garis besar, reformasi di bidang perpajakan bertujuan untuk; (1) optimalisasi penerimaan yang berkeadilan, meliputi perluasan tax base dan stimulus fiskal; (2) meningkatkan kepatuhan perpajakan melalui layanan prima dan penegakan hukum secara konsisten; (3) efisiensi administrasi berupa penerapan sistem dan administrasi andal dan pemanfaatan teknologi tepat guna; (4) terbentuknya citra yang baik dan tingkat kepercayaan masyarakat yang tinggi, melalui kapasitas SDM yang profesional, budaya organisasi yang kondusif, serta pelaksanaan good governance.

Sementara Peraturan Pemerintah mempertimbangkan reformasi perpajakan dalam rangka menghadapi dampak krisis keuangan global yang sangat mendesak untuk memperkuat basis perpajakan nasional guna mendukung penerimaan negara dari sektor perpajakan yang lebih stabil. Selain itu, juga masih banyak masyarakat yang ingin memanfaatkan fasilitas pengurangan atau penghapusan sanksi administrasi perpajakan sebagaimana diatur dalam Pasal 37 ayat (1) UU No. 28 Tahun 2007 tentang perubahan ketiga atas UU No.7 tahun1983 tentang Ketentuan Umum dan Tata Cara Perpajakan.

Untuk mencapai misi pemerintah tersebut, maka melalui UU No. 36 tentang Pajak Penghasilan tahun 2008 pemerintah memberi insentif dan kemudahan kepada pengusaha. Hal ini dapat mendorong para pengusaha untuk bersaing lebih kompetitif. Insentif dimaksud adalah : dengan menurunkan tarif Pajak Penghasilan yang dikenai tarif $28 \%$ mulai berlaku pada tahun fiskal 2009 dan akan menjadi 25 $\%$ mulai berlaku pada tahun fiskal 2010. Tarif PPh ini masih dapat dikurangi lagi sebesar 5\% apabila Wajib Pajak badan tersebut merupakan Wajib Pajak dalam negeri yang berbentuk perseroan terbuka yang paling sedikit $40 \%$ dari jumlah keseluruhan saham yang disetor diperdagangkan di Bursa Efek Indonesia dan atau lebih dari keseluruhan saham yang disetor dan saham tersebut dimiliki paling sedikit oleh 300 (tiga ratus) pihak.

Pemerintah berharap dengan adanya reformasi pajak, kinerja perpajakan akan semakin baik sehingga dapat membawa dampak positif bagi penerimaan pemerintah. Di sisi lain juga diharapkan agar reformasi tersebut dapat memberikan pengaruh positif kepada wajib pajak, baik wajib pajak orang pribadi maupun wajib pajak badan. Bagi wajib pajak badan, jika reformasi perpajakan tersebut membawa dampak yang positif tentunya akan mampu meningkatkan kinerja keuangan perusahaan, sementara jika reformasi perpajakan tersebut membawa dampak yang negatif maka akan menyebabkan perusahaan tidak dapat memperoleh laba secara maksimal sehingga menurunkan kinerja keuangan perusahaan.

\section{Tujuan Penelitian}

Tujuan penelitian ini adalah untuk mengetahui perbedaan profitabilitas berdasarkan Gross Profit Margin, Operating Profit Margin, Return on Investnent, dan Return on Equity sebelum dan sesudah diberlakukannya Undang-undang PPh No. 36 Tahun 2008.

\section{Pengertian Akuntansi}

\section{TINJAUAN PUSTAKA}

Menurut Libby, Libby dan Short (2008) akuntansi merupakan suatu system yang mengumpulkan dan memproses (menganalisis, menghitung dan mencatat) informasi keuangan mengenai sebuah organisasi dan melaporkan informasi tersebut kepada pengambil keputusan.

\footnotetext{
Akuntansi Keuangan

Menurut Libby, Libby dan Short (2008) akuntansi keuangan merupakan pengembangan akuntasi yang terfokus untuk pengambil keputusan eksternal.

\section{Analisis Rasio Keuangan}

Menurut Harahap (2007), analisis laporan keuangan berarti menguraikan akun-akun laporan keuangan menjadi unit informasi yang lebih kecil dan melihat hubungannya yang bersifat signifikan atau yang mempunyai makna antara yang satu dengan yang lain baik antara data kuantitatif maupun data nonkuantitatif dengan tujuan untuk mengetahui kondisi keuangan lebih dalam yang sangat penting dalam proses menghasilkan keputusan yang tepat.
} 


\section{Rasio Profitabilitas}

Rasio profitabilitas merupakan rasio yang menggambarkan kemampuan perusahaan dalam mendapatkan laba melalui semua kemampuan dan sumber yang ada seperti kegiatan penjualan, kas, modal, jumlah karyawan, jumlah cabang dan sebagainya (Syafri, 2008:304).

\section{Gross Profit Margin}

Gross profit margin merupakan rasio yang mengukur efisiensi pengendalian harga pokok atau biaya produksinya, mengindikasikan kemampuan perusahaan untuk berproduksi secara efisien (Sawir, 2009:18).

\section{Operating Profit Margin}

Operating profit margin merupakan rasio yang menggambarkan apa yang biasanya disebut pure profit yang diterima atas setiap rupiah dari penjualan yang dilakukan (Syamsuddin, 2009:61).

\section{Return on Investment}

Return on investment merupakan rasio yang mengukur kemampuan perusahaan secara keseluruhan di dalam menghasilkan keuntungan dengan jumlah keseluruhan aktiva yang tersedia didalam perusahaan (Syamsuddin, 2009:63).

\section{Return on Equity}

Return on equity merupakan suatu pengukuran dari penghasila/n (income) yang tersedia bagi para pemilik perusahaan (baik pemegang saham biasa maupun pemegang saham preferen) atas modal yang mereka investasikan di dalam perusahaan (Syafri, 2008:305).

\section{Definisi Pajak}

Menurut Undang-undang No. 28 Tahun 2007 tentang Perubahan Ketiga atas Undang-undang No. 6 Tahun 1983 tentang ketentuan Umum dan Tata Cara Perpajakan (KUP) Pasal 1 ayat (1) "Pajak adalah kontribusi wajib kepada negara yang terutang oleh orang pribadi atau badan yang bersifat memaksa berdasarkan Undang-Undang dengan tidak mendapatkan imbalan secara langsung, dan digunakan untuk keperluan negara bagi sebesar-besarnya kemakmuran rakyat”.

\section{Sejarah UU PPh No. 36 Tahun 2008}

Undang-Undang Pajak Penghasilan telah beberapa kali diubah, dimana perubahan pertama dilakukan pada tahun 1983. Berikut ini merupakan perubahan Undang-undang Pajak Penghasilan dari perubahan pertama sampai yang terbaru berdasarkan buku Undang-undang Republik Indonesia Tentang Pajak Penghasilan 2008 (2009) :

a. Undang-undang Republik Indonesia No.7 Tahun 1983 tentang Pajak Penghasilan.

b. Undang-undang Republik Indonesia No.7 Tahun 1991 tentang Perubahan Atas UURI No. 7 Tahun 1983 tentang Pajak Penghasilan.

c. Undang-undang Republik Indonesia No.10 Tahun 1994 tentang Perubahan Atas UURI No. 7 Tahun 1983 tentang Pajak Penghasilan sebagaimana telah diubah dengan UURI No. 7 Tahun 1991.

d. Undang-undang Republik Indonesia No.17 Tahun 2000 tentang Perubahan Ketiga Atas UURI No. 7 Tahun 1983 tentang Pajak Penghasilan. 
e. Undang-undang Republik Indonesia No.36 Tahun 2008 tentang Perubahan Keempat Atas UURI No. 7 Tahun 1983 tentang Pajak Penghasilan.

\section{Perubahan Tarif Pajak Penghasilan 2008}

Terdapat empat kali perubahan tarif Pajak Penghasilan Badan yaitu UU PPh tahun 1983 yang mulai berlaku tahun 1984, tarif UU PPh tahun 1994 yang mulai berlaku tahun 1995, UU PPh tahun 2000 yang mulai berlaku tahun 2001, dan UU PPh tahun 2008 yang mulai berlaku tahun 2009. Perubahan-perubahan tarif dari tahun ke tahun tersebut dapat dilihat pada tabel 1 di bawah ini :

Tabel 1. Perbedaan Tarif PPh Badan 1983, 1994, 2000, 2008

\begin{tabular}{|c|c|c|c|}
\hline $\begin{array}{l}\text { UU No.7 / } 1983 \\
\text { PKP dan Tarif }\end{array}$ & $\begin{array}{c}\text { UU No.10 / } 1994 \\
\text { PKP dan Tarif }\end{array}$ & $\begin{array}{c}\text { UU No.17 / } 2000 \\
\text { PKP dan Tarif }\end{array}$ & $\begin{array}{c}\text { UU No.36 / } 2008 \\
\text { PKP dan Tarif }\end{array}$ \\
\hline PKP s/d & PKP s/d & PKP s/d & \multirow{7}{*}{$\begin{array}{l}\text { Tarif Wajib Pajak Badan dan bentuk } \\
\text { usaha tetap adalah } 28 \% \text { dan bisa } \\
\text { turun sebesar 5\% untuk WP } \\
\text { berbentuk PT yang paling sedikit } \\
40 \% \text { dari jumlah keseluruhan saham } \\
\text { yang disetor, diperdagangkan di BEI } \\
\text { dan atau lebih dari keseluruhan } \\
\text { saham disetor dan saham tersebut } \\
\text { dimiliki paling sedikit } 300 \text { pihak. }\end{array}$} \\
\hline $10.000 .000=15 \%$ & $25.000 .000=10 \%$ & $50.000 .000=10 \%$ & \\
\hline PKP di atas & PKP di & PKP & \\
\hline $10.000 .000 \mathrm{~s} / \mathrm{d}$ & $25.000 .000 \mathrm{~s} / \mathrm{d}$ & $50.000 .000 \mathrm{~s} / \mathrm{d}$ & \\
\hline $50.000 .000=25 \%$ & $50.000 .000=15 \%$ & $100.000 .000=15 \%$ & \\
\hline PKP di atas & PKP di atas & PKP di atas & \\
\hline $50.000 .000=35 \%$ & $50.000 .000=30 \%$ & $100.000 .000=30 \%$ & \\
\hline
\end{tabular}

Penelitian Terdahulu

Tabel 2. Penelitian Terdahulu

\begin{tabular}{|c|c|c|c|c|c|c|c|}
\hline No. & $\begin{array}{l}\text { Peneliti/ } \\
\text { Tahun }\end{array}$ & Judul & Tujuan & $\begin{array}{l}\text { Metode } \\
\text { Penelitian }\end{array}$ & $\begin{array}{l}\text { Hasil } \\
\text { Penelitian }\end{array}$ & Persamaan & Perbedaan \\
\hline 1. & $\begin{array}{l}\text { Gunawan } \\
(2010)\end{array}$ & $\begin{array}{l}\text { Pengaruh } \\
\text { perubahan UU } \\
\text { No. } 36 \text { Tahun } \\
\text { 2008 Pasal } 17 \\
\text { Terhadap } \\
\text { Penerimaan PPh } \\
\text { Pasal } 21 \text { pada } \\
\text { Kantor Pelayanan } \\
\text { Pajak Pratama } \\
\text { Makasar Utara }\end{array}$ & $\begin{array}{l}\text { Menganalisis } \\
\text { pengaruh } \\
\text { perubahan UU } \\
\text { No. } 36 \text { Tahun } \\
2008 \text { pasal } 17 \\
\text { terhadap } \\
\text { penerimaan PPh } \\
\text { pasal } 21 \text { pada } \\
\text { KPP Pratama } \\
\text { Makasar Utara }\end{array}$ & $\begin{array}{l}\text { Statistik } \\
\text { deskriptif }\end{array}$ & $\begin{array}{l}\text { Berbeda } \\
\text { dengan } \\
\text { reformasi } \\
\text { pajak tahun } \\
2000 \text {, } \\
\text { perubahan } \\
\text { tarif dalam } \\
\text { UU No. } 36 \\
\text { Tahun } 2008 \\
\text { ternyata } \\
\text { memberikan } \\
\text { dampak } \\
\text { positif bagi } \\
\text { pendapatan } \\
\text { negara }\end{array}$ & $\begin{array}{l}\text { Menganalisis } \\
\text { pengaruh } \\
\text { perubahan UU } \\
\text { No. } 36 \text { Tahun } \\
2008\end{array}$ & $\begin{array}{l}\text { Terdapat } \\
\text { pada } \\
\text { penggunaan } \\
\text { variabel } \\
\text { sebagai alat } \\
\text { ukur dalam } \\
\text { melakukan } \\
\text { penelitian }\end{array}$ \\
\hline 2. & $\begin{array}{l}\text { Huda } \\
(2007)\end{array}$ & $\begin{array}{l}\text { Perbandingan } \\
\text { Kinerja Keuangan } \\
\text { Perusahaan } \\
\text { Manufaktur } \\
\text { Sebelum dan } \\
\text { Setelah } \\
\text { Diberlakukannya } \\
\text { UU Pajak Tahun } \\
\text { 2000 di Bursa } \\
\text { Efek Jakarta } \\
\text { (BEJ) }\end{array}$ & $\begin{array}{l}\text { Menganalisis } \\
\text { kinerja keuangan } \\
\text { perusahaan } \\
\text { manufaktur } \\
\text { sebelum dan } \\
\text { setelah } \\
\text { diberlakukannya } \\
\text { UU pajak tahun } \\
\text { 2000 di Bursa } \\
\text { Efek Jakarta } \\
\text { (BEJ) }\end{array}$ & $\begin{array}{l}\text { Statistik } \\
\text { deskriptif }\end{array}$ & $\begin{array}{l}\text { Secara umum } \\
\text { berlakunya } \\
\text { UU pajak No. } \\
17 \text { tahun } \\
2000 \text { sebagai } \\
\text { pengganti UU } \\
\text { pajak No. } 10 \\
\text { tahun } 1994 \\
\text { tidak } \\
\text { berpengaruh } \\
\text { signifikan } \\
\text { terhadap } \\
\text { kinerja } \\
\text { keuangan } \\
\text { perusahaan }\end{array}$ & $\begin{array}{l}\text { Menganalisis } \\
\text { kinerja } \\
\text { perusahaan } \\
\text { sebelum dan } \\
\text { setelah } \\
\text { diberlakukannya } \\
\text { UU perpajakan }\end{array}$ & $\begin{array}{l}\text { Terdapat } \\
\text { pada } \\
\text { penggunaan } \\
\text { variabel } \\
\text { sebagai alat } \\
\text { ukur dalam } \\
\text { melakukan } \\
\text { penelitian }\end{array}$ \\
\hline
\end{tabular}




\section{Hipotesis}

Dalam penelitian ini, peneliti menyusun hipotesis yaitu:

a. Ho : Tidak terdapat perbedaan profitabilitas berdasarkan Gross Profit Margin, Operating Profit Margin, Return on Investnent, dan Return on Equity sebelum dan sesudah diberlakukannya UU PPh No. 36 Tahun 2008.

b. Ha : Terdapat perbedaan profitabilitas berdasarkan Gross Profit Margin, Operating Profit Margin, Return on Investnent, dan Return on Equity sebelum dan sesudah diberlakukannya UU PPh No. 36 Tahun 2008.

\section{Jenis Penelitian}

\section{METODE PENELITIAN}

Jenis penelitian ini adalah analisis statistik deskriptif, yaitu suatu metode yang dilakukan dengan cara mengumpulkan, menyajikan, serta menganalisis data sehingga diperoleh gambaran yang cukup jelas tentang masalah yang dihadapi, kemudian ditarik suatu kesimpulan mengenai perhitungan, pencatatan, dan pelaporan. Dalam penelitian ini digunakan data kuantitatif, yaitu profitabilitas perusahaan yang dilihat dari Gross Profit Margin, Operating Profit Margin, Return on Investment dan Return on Equity sebelum dan sesudah diberlakukannya UU PPh Tahun 2008, yang pada tahun fiskal 2009 dikenai tarif pajak 28\% dan akan menjadi 25\% dimulai dari tahun fiskal 2010, yang kemudian dijadikan data kualitatif yaitu dengan mendeskripsikan angka-angka tersebut.

\section{Tempat dan Waktu Penelitian}

Dalam melakukan penelitian ini, peneliti menggunakan data sekunder yang di ambil dari Bursa Efek Indonesia (BEI) cabang Manado, yang terletak di Ruko Mega Smart Blok 1 No. 10, Komplek Mega Mas Jl. Piere Tendean, Boulevard Manado 95000, Indonesia.

Dalam menyelesaikan penelitian ini, peneliti memerlukan waktu 6 bulan, dimulai dari bulan Mei 2013 sampai dengan bulan Oktober 2013.

\section{Prosedur Penelitian}

Dalam proses penelitian, terdapat langkah-langkah yang dilakukan peneliti untuk menyelesaikan penelitian ini, yaitu :

a. Mengidentifikasi masalah.

b. Membuat hipotesis.

c. Studi literature.

d. Pengumpulan data.

e. Melakukan definisi operasional dan pengukuran variabel.

f. Menyusun desain penelitian.

g. Melakukan analisa statistik menggunakan SPSS v. 20

h. Menulis laporan hasil penelitian.

\section{Populasi dan Sampel}

Populasi dalam penelitian ini adalah seluruh perusahaan manufaktur yang go public di Bursa Efek Indonesia (BEI), yaitu sebanyak 170 perusahaan. Elemen populasi yang dipilih sebagai sampel dibatasi adalah sebanyak 60 perusahaan manufaktur yang go public di BEI selama 2 tahun sebelum dan sesudah diberlakukannya UU PPh No. 36 Tahun 2008. Adapun kriteria yang digunakan untuk pemilihan sampel tersebut sebagai berikut:

a. Terdaftar sebagai perusahaan manufaktur di BEI dari tahun 2008 sampai tahun 2012.

b. Memiliki kelengkapan informasi laporan keuangan dari tahun 2008 sampai dengan tahun 2012 yang dibutuhkan dalam penelitian.

\section{Metode Pengumpulan Data}

Data dalam penelitian ini dikumpulkan dengan menghitung dan mencatat data-data perusahaan manufaktur yang peneliti peroleh dari Bursa Efek Indonesia (BEI) cabang Manado dari tahun 2008 sampai tahun 2012.

\section{Metode Analisis Data}

Adapun metode analisis yang digunakan dalam penelitian ini adalah : 
a. Metode analisis deskriptif dengan pendekatan kuantitatif. Menggunakan pendekatan kuantitatif, artinya penelitian yang dilakukan adalah penelitian yang menekankan analisisnya pada data-data numeric (angka). Dalam penelitian ini data-data numeric (angka) berupa data-data laporan keuangan tahun 2009 dan 2010.

b. Metode analisis rasio yaitu metode analisis yang digunakan dengan menganalisis laporan keuangan pada tahun (periode) tertentu, yaitu dengan membandingkan antara pos yang satu dan pos lainnya dalam laporan keuangan. Rasio yang digunakan dalam penelitian ini adalah rasio profitabilitas, dengan variabel sebagai berikut :

I. Gross Profit Margin

II. Operating Profit Margin

III. Return on Investment

IV. Return on Equity

Setelah pengukuran masing-masing profitabilitas dilakukan, selanjutnya dilakukan pengujian statistik untuk membuktikan hipotesis yang telah dirumuskan. Proses pengujian hipotesisnya dapat menggunakan 2 cara sebagai berikut:

a. Proses pengujian hipotesis berdasarkan profitabilitas dengan prosedur sebagai berikut:

I. Tentukan hipotesis

Ho : Rata-rata nilai rasio yang dianalisis sebelum diberlakukannya UU PPh No. 36 Tahun 2008 dan sesudah diberlakukannya UU PPh No. 36 Tahun 2008 dalah sama.

Ha : Rata-rata nilai rasio yang dianalisis sebelum diberlakukannya UU PPh No. 36 Tahun 2008 dan sesudah diberlakukannya UU PPh No. 36 Tahun 2008 adalah berbeda.

II. Penentuan kesimpilan

$>$ Jika profitabilitas (tingkat signifikansi) $>0,005$ maka Ho diterima.

$>$ Jika profitabilitas (tingkat sgnifikansi) $<0,05$ maka Ha ditolak.

III.Pengambilan keputusan

b. Proses pengujian hipotesis berdasarkan nilai $t_{\text {tabel }}$ dengan prosedur sebagai berikut:

I. Tentukan hipotesis

Ho : Rata-rata nilai rasio yang dianalisis sebelum diberlakukannya UU PPh No. 36 Tahun 2008 dan sesudah diberlakukannya UU PPh No. 36 Tahun 2008 adalah sama.

Ha : Rata-rata nilai rasio yang dianalisis sebelum diberlakukannya UU PPh No. 36 Tahun 2008 dan sesudah diberlakukannya UU PPh No. 36 Tahun 2008 adalah berbeda.

II. Penentuan Kesimpulan

$>$ Jika nilai thitung $>$ ttabel 0,005 maka Ho ditolak.

$>$ Jika nilai thitung < ttabel 0,005 maka Ha diterima.

III.Pengambilan Keputusan

\section{Definisi Operasional dan Pengukuran Variabel}

Profitability merupakan tingkat keuntungan bersih yang mampu diraih oleh perusahaan pada saat menjalankan oprasinya. Semakin besar rasio ini berarti semakin tinggi kinerja suatu perusahaan. Profitability dalam penelitian ini diproksikan dengan GPM, OPM, ROI dan ROE.

a. Gross Profit Margin 
Gross profit margin merupakan perbandingan antara penjualan bersih dikurangi dengan harga pokok penjualan dengan tingkat penjualan, rasio ini menggambarkan laba kotor yang dapat dicapai dari jumlah penjualan. Rumus GPM yaitu :

b. Operating Profit Margin

Operating profit margin merupakan perbandingan antara laba usaha dan penjualan. Operating profit disebut murni (pure) dalam pengertian bahwa jumlah tersebutlah yang benarbenar diperoleh dari hasil operasi perusahaan dengan mengabaikan kewajiban-kewajiban finansial berupa bunga serta kewajiban terhadap pemerintah berupa pembayaran pajak.

c. Return on Investment (ROI)

Return on investment merupakan perbandingan antara laba bersih setelah pajak dengan total aktiva. Return on investment merupakan rasio yang mengukur kemampuan perusahaan secara keseluruhan di dalam menghasilkan keuntungan dengan jumlah keseluruhan aktiva yang tersedia didalam perusahaan (Syamsuddin, 2009:63).

d. Return on Equity (ROE)

Return on equity merupakan perbandingan antara laba bersih sesudah pajak dengan total ekuitas. Return on equity merupakan suatu pengukuran dari penghasilan (income) yang tersedia bagi para pemilik perusahaan (baik pemegang saham biasa maupun pemegang saham preferen) atas modal yang mereka investasikan di dalam perusahaan (Syafri, 2008:305).

\section{Hasil Penelitian}

\section{HASIL PENELITIAN DAN PEMBAHASAN}

\section{Tabel 3. Daftar Perusahaan Manufaktur}

\begin{tabular}{|c|c|c|c|c|c|c|c|c|c|}
\hline \multirow{2}{*}{ No } & \multirow{2}{*}{ Perusahaan } & \multicolumn{4}{|c|}{2009} & \multicolumn{4}{|c|}{2010} \\
\hline & & GPM & OPM & ROI & ROE & GPM & OPM & ROI & ROE \\
\hline 1 & PT Cahaya Kalbar Tbk. & 0.12 & 0.08 & 8.70 & 16.42 & 0.12 & 0.06 & 3.48 & 9.57 \\
\hline 2 & PT Delta Djakarta Tbk. & 0.46 & 0.22 & 16.64 & 21.10 & 0.66 & 0.33 & 20.61 & 24.62 \\
\hline 3 & PT Indofood CBP Sukses Makmur Tbk. & 0.24 & 0.11 & 10.55 & 66.36 & 0.28 & 0.15 & 13.75 & 19.62 \\
\hline 4 & PT Indofood Sukses Makmur Tbk. & 0.28 & 0.13 & 6.75 & 17.59 & 0.32 & 0.18 & 8.50 & 16.16 \\
\hline 5 & PT Gudang Garam Tbk. & 0.22 & 0.16 & 12.69 & 18.88 & 0.24 & 0.16 & 13.71 & 19.88 \\
\hline 6 & PT Roda Vivatex Tbk. & 0.52 & 0.47 & 15.75 & 19.21 & 0.54 & 0.49 & 10.05 & 23.92 \\
\hline 7 & PT Indorama Syntetics Tbk. & 0.06 & 0.01 & 2.06 & 5.06 & 0.10 & 0.04 & 2.06 & 5.06 \\
\hline 8 & PT Pan Brothers Tex Tbk. & 0.10 & 0.03 & 4.06 & 25.20 & 0.11 , & 0.04 & 4.02 & 21.30 \\
\hline 9 & PT Ricky Putra Globalindo Tbk. & 0.15 & 1.55 & 0.60 & 1.09 & 0.19 & 3.41 & 1.76 & 3.20 \\
\hline & PT Sepatu Bata Tbk. & 0.46 & 0.13 & 1.27 & 17.58 & 0.48 & 0.14 & 12.59 & 18.39 \\
\hline & PT Fajar Surya Wisesa Tbk. & 0.20 & 0.16 & 7.45 & 17.46 & 0.19 & 0.15 & 6.30 & 15.63 \\
\hline & PT Suparma Tbk. & 0.12 & 0.06 & 1.88 & 3.91 & 0.15 & 0.09 & 1.99 & 4.12 \\
\hline & PT Budi Acid Jaya Tbk. & 0.15 & 0.09 & 9.16 & 18.71 & 0.11 & 0.06 & 2.34 & 5.75 \\
\hline & PT Eterindo Wahanatama Tbk. & 0.04 & 0.02 & 1.94 & 3.93 & 0.08 & 0.04 & 7.15 & 12.59 \\
\hline & PT Trias Sentosa Tbk. & 0.17 & 0.10 & 7.49 & 12.57 & 0.17 & 0.11 & 6.74 & 11.04 \\
\hline & PT Yanaprima Hastapersada Tbk. & 0.16 & 0.11 & 9.70 & 14.99 & 0.14 & 0.10 & 10.55 & 16.11 \\
\hline & PT Semen Gresik (Persero) Tbk. & 0.47 & 0.30 & 25.68 & 32.22 & 0.47 & 0.31 & 23.51 & 30.14 \\
\hline & PT Betonjaya Manunggal Tbk. & 0.17 & 0.13 & 13.45 & 14.53 & 0.13 & 0.09 & 9.34 & 11.47 \\
\hline & PT Citra Tubindo Tbk. & 0.16 & 0.09 & 7.12 & 13.10 & 0.24 & 0.14 & 6.71 & 16.23 \\
\hline & PT Jaya Pari Steel Tbk. & 0.12 & 0.07 & 0.54 & 0.71 & 0.13 & 0.09 & 6.92 & 9.48 \\
\hline & PT Lion Mesh Prima Tbk. & 0.08 & 0.03 & 33.30 & 6.04 & 0.11 & 0.07 & 9.40 & 10.26 \\
\hline & PT Hexindo Adiperkasa Tbk. & 0.18 & 0.11 & 13.08 & 25.73 & 0.19 & 0.11 & 17.04 & 32.72 \\
\hline & PT Intraco Penta Tbk. & 0.20 & 0.07 & 3.20 & 9.96 & 0.17 & 0.08 & 5.17 & 19.35 \\
\hline & PT Nipress Tbk. & 0.14 & 0.03 & 1.17 & 2.90 & 0.15 & 0.06 & 3.75 & 8.55 \\
\hline & PT. Indospring Tbk. & 0.13 & 0.03 & 9.46 & 35.47 & 0.20 & 0.12 & 9.10 & 30.94 \\
\hline & PT Tunas Ridean Tbk. & 0.09 & 0.04 & 17.53 & 31.03 & 0.08 & 0.04 & 12.81 & 22.17 \\
\hline & PT United Tractor Tbk. & 0.23 & 0.18 & 15.64 & 27.36 & 0.18 & 0.14 & 13.21 & 24.28 \\
\hline & PT Astra Graphia Tbk. & 0.29 & 0.08 & 8.64 & 17.57 & 0.29 & 0.10 & 12.00 & 25.36 \\
\hline 29 & PT Astra Otoparts Tbk. & 0.18 & 0.08 & 16.54 & 22.71 & 0.18 & 0.09 & 21.96 & 29.89 \\
\hline
\end{tabular}




\begin{tabular}{|c|c|c|c|c|c|c|c|c|c|}
\hline \multirow{2}{*}{ No } & \multirow{2}{*}{ Perusahaan } & \multicolumn{4}{|c|}{2009} & \multicolumn{4}{|c|}{2010} \\
\hline & & GPM & OPM & ROI & ROE & GPM & OPM & ROI & ROE \\
\hline & PT Mayora Indah Tbk. & 0.24 & 0.13 & 11.86 & 23.73 & 0.24 & 0.11 & 11.41 & 24.60 \\
\hline 31 & PT Fast Food IndonesiaTbk. & 0.60 & 0.09 & 17.48 & 28.48 & 0.56 & 0.07 & 16.15 & 24.90 \\
\hline & PT Nippon Indosari Corpindo Tbk. & 0.46 & 0.18 & 16.46 & 34.03 & 0.47 & 0.21 & 17.56 & 21.91 \\
\hline & PT Siantar Top Tbk. & 0.16 & 0.6 & 7.49 & 10.15 & 0.17 & 0.07 & 6.57 & 9.53 \\
\hline & PT Tiga Pilar Sejahtera Food Tbk. & 0.29 & 19.25 & 2.41 & 5.79 & 0.26 & 17.92 & 4.13 & 13.25 \\
\hline & PT Ultra Milk Industry Tbk. & 0.26 & 0.08 & 3.53 & 5.12 & 0.31 & 0.10 & 5.34 & 8.23 \\
\hline 36 & PT Astra International Tbk. & 0.23 & 0.13 & 11.29 & 25.17 & 0.21 & 0.11 & 12.73 & 29.13 \\
\hline & PT Hanjaya Mandala Sampoerna Tbk. & 0.29 & 0.19 & 28.72 & 48.61 & 0.29 & 0.20 & 31.37 & 63.02 \\
\hline & PT Panasia Indo Resources Tbk. & 0.04 & 0.03 & 0.05 & 0.10 & 7,00 & 3,00 & 3,00 & 6,00 \\
\hline & PT Star Petrochem Tbk. & 0.07 & 0.03 & 24.89 & 76.21 & 0.09 & 0.06 & 0.75 & 1.25 \\
\hline & PT Trisula InternasionalTbk. & 0.20 & 0.06 & 0.87 & 1.98 & 0.17 & 0.04 & 1.68 & 3.18 \\
\hline & PT Ever Shine Tex Tbk. & 6,00 & 0.01 & 1.48 & 2.99 & 0.06 & 0.02 & 0.25 & 0.58 \\
\hline & PT Indo Acidatama Tbk. & 0.25 & 0.13 & 6.13 & 11.62 & 0.20 & 0.07 & 2.70 & 4.31 \\
\hline & PT Indah Kiat Pulp \& Paper Tbk. & 0.18 & 0.08 & 0.22 & 0.65 & 0.18 & 0.08 & 0.22 & 0.65 \\
\hline & PT AKR Corporindo Tbk. & 0.11 & 0.06 & 4.53 & 12.31 & 0.06 & 0.03 & 4.06 & 10.88 \\
\hline & PT Lautan Luas Tbk. & 0.15 & 0.04 & 2.79 & 8.99 & 0.16 & 0.04 & 2.88 & 10.13 \\
\hline & PT Unggul Indah CahayaTbk. & 0.09 & 0.01 & 1.75 & 3.14 & 0.08 & 0.02 & 2.36 & 4.33 \\
\hline & PT Ekadarma Internasional Tbk. & 0.26 & 0.13 & 9.96 & 18.49 & 0.27 & 0.15 & 20.17 & 32.93 \\
\hline & PT Resources Alam Indonesia Tbk. & 0.35 & 0.11 & 11.73 & 21.22 & 0.35 & 0.24 & 31.49 & 54.11 \\
\hline & PT Langgeng Makmur Industri Tbk. & 0.17 & 0.05 & 1.11 & 1.50 & 0.18 & 0.04 & 0.46 & 0.70 \\
\hline & PT Indocement Tunggal Prakarsa Tbk. & 0.48 & 0.35 & 20.69 & 25.66 & 0.50 & 0.36 & 21.01 & 24.61 \\
\hline & PT Lion Metal Works Tbk. & 0.45 & 0.22 & 12.39 & 14.76 & 0.45 & 0.23 & 12.71 & 14.86 \\
\hline & PT Tira Austenite Tbk. & 0.36 & 0.08 & 1.09 & 2.66 & 0.35 & 0.06 & 2.33 & 5.31 \\
\hline & PT Kedawung Setia Industrial Tbk. & 0.12 & 0,03 & 1.91 & 4.40 & 0.12 & 0.03 & 3.03 & 6.61 \\
\hline & PT Surya Toto Indonesia Tbk. & 0.30 & 0.22 & 18.09 & 34.58 & 0.31 & 0.23 & 17.81 & 30.81 \\
\hline & PT Kabelindo Murni Tbk. & 0.08 & 2,80 & 0.48 & 0.76 & 0.06 & 2.23 & 0.96 & 1.71 \\
\hline & PT Prima Alloy Steel Universal Tbk. & 0.08 & 0.03 & 3.30 & 6.04 & 0.11 & 0.07 & 9.40 & 10.26 \\
\hline & PT Goodyear Indonesia Tbk. & 0.16 & 0.10 & 10.05 & 29.26 & 0.10 & 0.05 & 5.81 & 16.04 \\
\hline & PT Indo Kordsa Tbk. & 0.16 & 0.10 & 5.34 & 6.41 & 0.17 & 0.12 & 11.04 & 13.64 \\
\hline & PT Selamat Sempurna Tbk. & 0.23 & 0.14 & 14.11 & 24.45 & 0.24 & 0.15 & 15.45 & 29.04 \\
\hline & PT Polychem Indonesia Tbk. & 0.02 & 0.02 & 1.45 & 4.94 & 0.16 & 0.03 & 0.78 & 1.65 \\
\hline
\end{tabular}

\section{Hasil Profitabilitas Nilai GPM, OPM, ROI, dan ROE Sebelum dan Sesudah Diberlakukannya UU PPh No.36 Tahun 2008}

Untuk menganalisis perbedaan kondisi profitabilitas perusahaan manufaktur yang go public di Bursa Efek Indonesia sebelum dan sesudah UU PPh No. 36 Tahun 2008, maka sesuai dengan hasil pengujian secara statistik, diperoleh hasil sebagai berikut.

\section{a. Gross Profit Margin}

\begin{tabular}{|c|c|c|c|c|c|c|c|c|c|}
\hline \multicolumn{10}{|c|}{ Tabel 4. Paired Samples Test GPM } \\
\hline & & \multicolumn{5}{|c|}{ Paired Differences } & \multirow{3}{*}{$\mathrm{t}$} & \multirow{3}{*}{$\mathrm{df}$} & \multirow{3}{*}{$\begin{array}{l}\text { Sig. (2- } \\
\text { tailed) }\end{array}$} \\
\hline & & \multirow[t]{2}{*}{ Mean } & \multirow[t]{2}{*}{$\begin{array}{c}\text { Std. } \\
\text { Deviation }\end{array}$} & \multirow{2}{*}{$\begin{array}{l}\text { Std. } \\
\text { Error } \\
\text { Mean }\end{array}$} & \multicolumn{2}{|c|}{$\begin{array}{l}\text { 95\% Confidence } \\
\text { Interval of the } \\
\text { Difference }\end{array}$} & & & \\
\hline & & & & & Lower & Upper & & & \\
\hline Pair 1 & $\begin{array}{l}\text { Tahun2009 - } \\
\text { Tahun2010 }\end{array}$ &,- 9333 & 4,18175 &, 5399 & $-2,0136$ & , 14693 & $-1,729$ & 59 & 089 \\
\hline
\end{tabular}

Dari hasil perhitungan seperti yang tampak pada tabel 4.7 dapat diketahui bahwa nilai $\mathrm{t}_{\text {hitung }}<$ $\mathrm{t}_{\text {tabel }}(1,729<2,045)$ pada $\alpha=0,05$. 
b. Operating Profit Margin

Tabel 5. Paired Samples Test OPM

\begin{tabular}{|c|c|c|c|c|c|c|c|c|c|}
\hline & & \multicolumn{5}{|c|}{ Paired Differences } & \multirow{3}{*}{$\mathrm{t}$} & \multirow{3}{*}{$\mathrm{df}$} & \multirow{3}{*}{$\begin{array}{l}\text { Sig. (2- } \\
\text { tailed) }\end{array}$} \\
\hline & & \multirow[t]{2}{*}{ Mean } & \multirow[t]{2}{*}{$\begin{array}{c}\text { Std. } \\
\text { Deviation }\end{array}$} & \multirow{2}{*}{$\begin{array}{l}\text { Std. } \\
\text { Error } \\
\text { Mean }\end{array}$} & \multicolumn{2}{|c|}{$\begin{array}{l}95 \% \text { Confidence } \\
\text { Interval of the } \\
\text { Difference }\end{array}$} & & & \\
\hline & & & & & Lower & Upper & & & \\
\hline Pair 1 & $\begin{array}{l}\text { Tahun2009 } \\
\text { Tahun2010 }\end{array}$ & - - -,91667 & 30,857 & 3,9837 & $-8,8879$ & 7,0546 &,- 230 & 59 & ,819 \\
\hline
\end{tabular}

Dari hasil perhitungan seperti yang tampak pada tabel 4.8 dapat diketahui bahwa nilai $\mathrm{t}_{\text {hitung }}<$ $\mathrm{t}_{\text {tabel }}(0,230<2,045)$ pada $\alpha=0,05$.

\section{c. Return on Investment}

\begin{tabular}{|c|c|c|c|c|c|c|c|c|c|}
\hline \multicolumn{10}{|c|}{ Tabel 6. Paired Samples Test ROI } \\
\hline & & \multicolumn{5}{|c|}{ Paired Differences } & \multirow{3}{*}{$\mathrm{t}$} & \multirow{3}{*}{ Df } & \\
\hline & & \multirow[t]{2}{*}{ Mean } & \multirow[t]{2}{*}{$\begin{array}{c}\text { Std. } \\
\text { Deviation }\end{array}$} & \multirow[t]{2}{*}{$\begin{array}{l}\text { Std. } \\
\text { Error } \\
\text { Mean }\end{array}$} & \multicolumn{2}{|c|}{$\begin{array}{l}95 \% \text { Confidence } \\
\text { Interval of the } \\
\text { Difference }\end{array}$} & & & $\begin{array}{l}\text { S1g. } \\
(2- \\
\text { tailed }\end{array}$ \\
\hline & & & & & Lower & Upper & & & \\
\hline Pair 1 & $\begin{array}{l}\text { Tahun2009 } \\
\text { Tahun2010 }\end{array}$ & $-3,383$ & 596,782 & 77,044 & $-157,548$ & 150,782 &,- 044 & 59 & ,965 \\
\hline
\end{tabular}

Dari hasil perhitungan seperti yang tampak pada tabel 4.9 dapat diketahui bahwa nilai $\mathrm{t}_{\text {hitung }}<$ $\mathrm{t}_{\text {tabel }}(0,044<2,045)$ pada $\alpha=0,05$.

\section{d. Return on Equity}

\begin{tabular}{|c|c|c|c|c|c|c|c|c|c|}
\hline \multicolumn{10}{|c|}{ Tabel 7. Paired Samples Test ROE } \\
\hline & & \multicolumn{5}{|c|}{ Paired Differences } & \multirow{3}{*}{$\mathrm{t}$} & \multirow{3}{*}{ df } & \multirow{3}{*}{$\begin{array}{l}\text { Sig. } \\
(2- \\
\text { tailed })\end{array}$} \\
\hline & & \multirow[t]{2}{*}{ Mean } & \multirow[t]{2}{*}{$\begin{array}{c}\text { Std. } \\
\text { Deviation }\end{array}$} & \multirow[t]{2}{*}{$\begin{array}{l}\text { Std. Error } \\
\text { Mean }\end{array}$} & \multicolumn{2}{|c|}{$\begin{array}{l}95 \% \text { Confidence } \\
\text { Interval of the } \\
\text { Difference }\end{array}$} & & & \\
\hline & & & & & Lower & Upper & & & \\
\hline Pair 1 & $\begin{array}{l}\text { Tahun2009 } \\
\text { Tahun2010 }\end{array}$ & 72,617 & 1349,540 & 174,225 & $-276,006$ & 421,240 & , 417 & 59 & ,678 \\
\hline
\end{tabular}

Dari hasil perhitungan seperti yang tampak pada tabel 4.10 dapat diketahui bahwa nilai $\mathrm{t}_{\text {hitung }}<$ $\mathrm{t}_{\text {tabel }}(0,417<2,045)$ pada $\alpha=0,05$.

\section{Pembahasan}

\section{a. Gross Profit Margin}

Tidak terdapat pengaruh yang signifikan antara rata-rata nilai GPM sebelum dan sesudah diberlakukannya UU PPh No. 36 Tahun 2008 pada Tahun 2010 dan 2011. Sehingga dapat dinyatakan bahwa UU PPh No. 36 Tahun 2008 tidak berpengaruh terhadap perkembangan nilai GPM yang berhasil dicapai oleh perusahaan manufaktur yang go public di Bursa Efek Indonesia (BEI).

\section{b. Operating Profit Margin}

Tidak terdapat pengaruh yang signifikan antara rata-rata nilai OPM sebelum dan sesudah diberlakukannya UU PPh No. 36 Tahun 2008 pada Tahun 2010 dan 2011. Sehingga dapat dinyatakan bahwa UU PPh No. 36 Tahun 2008 tidak berpengaruh terhadap perkembangan nilai OPM yang berhasil dicapai oleh perusahaan manufaktur yang go public di Bursa Efek Indonesia (BEI).

\section{c. Return on Investment}

Tidak terdapat pengaruh yang signifikan antara rata-rata nilai ROI sebelum dan sesudah diberlakukannya UU PPh No. 36 Tahun 2008 pada Tahun 2010 dan 2011. Sehingga dapat dinyatakan bahwa UU PPh No. 36 Tahun 2008 tidak berpengaruh terhadap perkembangan nilai 
ROI yang berhasil dicapai oleh perusahaan manufaktur yang go public di Bursa Efek Indonesia (BEI).

\section{d. Return on Equity}

Tidak terdapat pengaruh yang signifikan antara rata-rata nilai ROE sebelum dan sesudah diberlakukannya UU PPh No. 36 Tahun 2008 pada Tahun 2010 dan 2011. Sehingga dapat dinyatakan bahwa UU PPh No. 36 Tahun 2008 tidak berpengaruh terhadap perkembangan nilai ROE yang berhasil dicapai oleh perusahaan manufaktur yang go public di Bursa Efek Indonesia (BEI).

\section{Kesimpulan}

\section{PENUTUP} berikut:

Dari hasil penelitian dan pembahasan maka dapat diambil beberapa kesimpulan sebagai

a. Hasil uji coba beda menunjukan bahwa tidak terdapat perbedaan yang signifikan antara Gross Profit Margin sebelum dan sesudah diberlakukannya UU PPh No. 36 Tahun 2008 pada Tahun 2010 dan 2011. Dengan nilai $\mathrm{t}_{\text {hitung }}<\mathrm{t}_{\text {tabel }}(1,729<2,045)$ pada $\alpha=0,05$.

b. Hasil uji coba beda menunjukan bahwa tidak terdapat perbedaan yang signifikan antara Operating Profit Margin sebelum dan sesudah diberlakukannya UU PPh No. 36 Tahun 2008 pada Tahun 2010 dan 2011. Dengan nilai $t_{\text {hitung }}<\mathrm{t}_{\text {tabel }}(0,230<2,045)$ pada $\alpha=0,05$.

c. Hasil uji coba beda menunjukan bahwa tidak terdapat perbedaan yang signifikan antara Return On Investment sebelum dan sesudah diberlakukannya UU PPh No. 36 Tahun 2008 pada Tahun 2010 dan 2011. Dengan nilai $\mathrm{t}_{\text {hitung }}<\mathrm{t}_{\text {tabel }}(0,044<2,045)$ pada $\alpha=0,05$.

d. Hasil uji coba beda menunjukan bahwa tidak terdapat perbedaan yang signifikan antara Return On Equity sebelum dan sesudah diberlakukannya UU PPh No. 36 Tahun 2008 pada Tahun 2010 dan 2011. Dengan nilai $\mathrm{t}_{\text {hitung }}<\mathrm{t}_{\text {tabel }}(0,417<2,045)$ pada $\alpha=0,05$.

\section{Saran}

Berdasarkan kesimpulan yang telah diuraikan, maka penulis dapat mengemukakan saran-saran sebagai berikut :

a. Disarankan agar perusahaan-perusahaan manufaktur yang go public di Bursa Efek Indonesia (BEI) mempertahankan bahkan meningkatkan kinerja usahanya agar kemampuan mereka untuk memperoleh laba semakin meningkat dengan adanya lapisan tarif pajak yang baru yaitu UU PPh N0.36 Tahun 2008, dengan cara berupaya meningkatkan efisiensi dan produktifitas perusahaanperusahaan manufaktur yang go public di Bursa Efek Indonesia (BEI).

b. Disarankan pula agar kemampuan dan keinginan perusahaan-perusahaan yang go public di Bursa Efek Indonesia (BEI) dalam meningkatkan nilai GPM, OPM, ROI, dan ROE tetap dipertahankan karena berdasarkan lapisan tarif pajak yang baru yaitu UU PPh No. 36 Tahun 2008 GPM, OPM, ROI, dan ROE tidak mengalami perubahan nilai profitabilitas yang signifikan. 


\section{DAFTAR PUSTAKA}

Harahap SS, 2007. Analisis Kritis Atas Laporan Keuangan. PT. Raja Grafindo Persada, Jakarta. Ikatan Akuntasi Indonesia, 2009. Standar Akuntansi Keuangan. Salemba Empat. Jakarta.

Ilyas, Wirawan B. dan Rudy Suhartono, 2007. Panduan Komprehensif dan Praktis Ketentuan Umum dan Tata Cara Perpajakan (KUP). Salemba Empat. Jakarta.

Ilyas, Wirawan B. dan Rudy Suhartono, 2010. Panduan Komprehensif dan Praktis Pajak Penghasilan. Lembaga Penerbit Fakultas Ekonomi Universitas Indonesia. Jakarta.

Kasmir, 2009. Analisis Laporan Keuangan. PT. Rajawali Pers. Jakarta.

Libby, Libby, \& Short, 2008. Akuntansi Keuangan. Andi. Jakarta.

Manopo Fenty, 2012. Junal: "Analisis Rasio Likuiditas dan Rasio Profitabilitas Untuk Menilai Kinerja Keuangan pada PT. Telekomunikasi Indonesia Tbk."

Mardiasmo, 2009. Perpajakan. Andi. Jakarta.

Margono, 2007. Metodologi Penelitian Pendidikan. Rineka Cipta. Jakarta.

Sawir, 2011. Analisis Kinerja Keuangan dan Perencanaan Keuangan Perusahaan. Gramedia. Jakarta. Sugiyono, 2010. Akuntansi \& Pelaporan Keuangan. Grasindo. Jakarta.

Sutrisno, 2009. Manajemen Keuangan: Teori, Konsep \& Aplikasi. Ekonisia. Jakarta.

Syafri, 2011. Analisis Kritis Atas Laporan Keuangan. Raja Grafindo Persada. Jakarta.

Syamsuddin, 2009. Manajemen Keuangan Perusahaan. Rajawali Pers. Jakarta. . 2011. Buku Panduan Bendahara. Kementrian Keuangan Republik Indonesia Direktorat Jenderal Pajak Kantor Wilayah Sulawesi Utara, Tengah, Gorontalo dan Maluku Utara. Manado.

. 2009. UU Republik Indonesia tentang Pajak Penghasilan 2008. CV.Novindo Pustaka Mandiri. Jakarta. 